\title{
What is Performance Measurement for? Multiple Uses of Performance Information within Organizations
}

\author{
Pietro Micheli \\ Warwick Business School, University of Warwick, Coventry, CV4 7AL, UK \\ T:+44 (0)247615 0882; E: pietro.micheli@wbs.ac.uk \\ Andrey Pavlov \\ School of Management, Cranfield University, Cranfield, Bedfordshire MK430AL, UK \\ T:+44 (0)1234 751122; E: andrey.pavlov@cranfield.ac.uk
}

\begin{abstract}
Recent research in performance measurement has focused on the tension between two uses of performance information: 'passive', to ensure compliance, and 'purposeful', to improve services. This article presents an in-depth study of two public sector organizations in England and shows that the main tension may actually lie between a combined purposeful and passive use, and an exclusively passive one. This tension was most pronounced between organizational levels, where a combined use was dominant among senior managers, and an exclusively passive one was prevalent among middle managers and frontline staff. This split was not intentional - instead, it reflected how people interpreted the role of performance measurement, suggesting that simply promoting greater use of information may not be sufficient for linking measurement with service improvement. This study extends the theoretical understanding of the dynamics of performance information use in organizations and generates implications for using performance measurement to improve service delivery.
\end{abstract}




\section{INTRODUCTION}

Over the past three decades, governments have made substantial investments to design and implement performance measurement systems at both national and local levels (Bevan and Hood 2006; Moynihan and Kroll 2016). The concept of performance has permeated public sector reforms (Van Dooren et al. 2010), and the use of measurement systems is becoming ubiquitous around the world (Johnston and Pongatichat 2008; Arnaboldi et al. 2015; Li 2015).

Recent research has identified the use of performance information as a critical factor in explaining the effectiveness of performance measurement programmes (Taylor 2011a; Lavertu and Moynihan 2013). Indeed, the use of performance information has been regarded as the ultimate test of performance reforms, assuming that public officials will make better decisions through the regular use of such information (Taylor 2009).

While significant effort has been devoted to explaining the extent and drivers of performance information use, a number of studies have found that organizations utilize performance information in different ways (Moynihan et al. 2011). For example, the typology of performance information uses adopted in most recent empirical studies (see, e.g., Kroll and Vogel 2014; Moynihan and Kroll 2016) identifies several kinds, the two attracting the most attention being 'passive', which refers to employees' use of performance information mainly to report and comply, and 'purposeful', which indicates the use of information with the main aim of improving performance (Moynihan 2009).

While these are ideal types and organizations may be expected to use information in multiple ways, little is known about how different uses are introduced and how they relate to each other. Several scholars have investigated the antecedents of performance information use, specifically of a 'purposeful' kind, and policy makers have attempted to strengthen the link between performance information use and service improvement (Kroll and Vogel 2014). 
However, there still remains evidence that 'agencies use performance indicators more for meeting external reporting requirements than for achieving internal improvements' (Taylor 2011a, p. 860), suggesting that simply promoting the use of performance information may not lead to service improvement.

This research sets out to explore the interplay of passive and purposeful uses in organizations. It examines the uses of performance information in two organizations in England - a local authority and a fire authority - in a period when performance measurement was regarded as a key means to improve performance (Bevan and Hood 2006; Döring et al. 2015). Moreover, senior management devoted substantial efforts to promoting a purposeful use within both organizations (Moynihan et al. 2012). More specifically, this research is guided by the following questions: how do passive and purposeful uses interact? And what implications does this interaction have for the overall aim of using performance information to improve services?

This article generates four main findings. First, tensions were identified not between separate uses (i.e., purposeful vs. passive), but between a combined purposeful and passive use on one hand, and an exclusively passive use on the other. Second, these tensions were most pronounced between hierarchical roles. Senior managers tended to use performance information in a combined way, whereas frontline employees utilized it mainly for reporting and compliance. Third, the decoupling between combined and exclusively passive use appeared to be neither strategic nor intentional, but principally the consequence of divergent interpretations of the goals and purposes of performance measurement. Such diversity in interpretations contributes to explaining the lack of use of performance information by frontline staff to achieving service improvement. Finally, the results indicate that differences in use are distinct and persistent. This suggests that, on its own, an emphasis on performance measurement and on greater use of information is unlikely to lead to the desired kind of use. 
Instead, getting the frontline staff to see beyond the passive use may require efforts to help them reconsider assumptions and reinterpret the role of performance information.

\section{MEASURING AND MANAGING PERFORMANCE}

In principle, a performance measurement system should perform the double function of an information acquisition and an information representation system (Mari 2007). Therefore, such a system should provide accurate, complete and trustworthy performance information, which could support decision-making processes and actions, thus helping organizations manage and improve their performance (Micheli and Mari 2014).

This rational approach to monitoring and improving government performance has driven various reforms in Western European countries (see, e.g., Van Dooren et al. 2010; Arnaboldi et al. 2015), retaining its appeal in specific sectors such as education (Teelken 2015; Destler 2017) and expanding its reach to other regions of the world (Cheung 2011; Li 2015; Ma 2016). However, it has been repeatedly shown that simply introducing and refining measurement systems does not contribute directly to performance improvement (Taylor 2009; Gerrish 2016). Thus, empirical studies have increasingly questioned the link between the production and use of performance information. As Moynihan et al. (2011, p. i149) put it, 'how do we make the jump from measurement to management? Until data are interpreted and used, the promise of performance regimes to improve performance will not be met'.

\section{USE OF PERFORMANCE INFORMATION}

The use of performance information has been characterized as the 'big question for the performance management movement' (Moynihan and Lavertu 2012, p. 592), and as an 
'intermediate step on the way to better performance' (Bryson 2012, p. S106). However, despite increasing investments in the design and implementation of measurement systems, the use of performance information remains limited. The academic literature has examined this issue in a number of contexts, including the UK (see, e.g., Bovaird and Gregory 1996; Bevan and Hood 2006), continental Europe (Speklé and Verbeeten 2014; Arnaboldi et al. 2015), Australia (Taylor 2011a and 2001b) and the U.S. (Moynihan and Kroll 2016). The importance of performance information use has led researchers to employ it as the dependent variable in their studies (see, e.g., Kroll and Moynihan 2015). Consequently, a recent and steadily growing stream of literature has concentrated on uncovering the factors that could promote greater use of performance information. For example, Taylor (2011b) found that the type of measurement system, organizational culture, external environment, and attitudes towards the impact of performance indicators were significantly related to the use of performance information for decision-making. Other authors also highlighted that perceived leadership commitment to results might be positively associated with use as 'leaders "set the table" for performance information use via a positive but indirect effect on two mediating factors, goal clarity and organizational culture' (Moynihan et al. 2012, p. 143).

At the same time, focusing simply on increasing the use of performance information may be misleading, as uses may be different. For example, Bovaird and Gregory (1996) recognized four managerial roles for performance measurement: giving strategic direction, resource allocation, exercising control, and encouraging learning. Behn's (2003) distinguished eight purposes: evaluate, budget, control, motivate, promote, celebrate, learn and improve. Later, Van Dooren et al. (2010) identified accountability, learning, steering and controlling as reasons for using performance information. However, it was Moynihan's (2009) research that focused specifically on the different uses of performance information. 


\section{PURPOSEFUL AND PASSIVE USES}

Moynihan (2009) proposed a fundamental distinction between two types of uses: purposeful (performance information is used to improve efficiency and effectiveness), and passive (information is utilized to comply with procedural requirements). Despite these being ideal types, which are likely to co-exist in reality, earlier studies have juxtaposed them, with the purposeful use being described as the most desirable type, and the passive use being seen mainly as dysfunctional (Kroll and Vogel 2014).

Seen in light of Moynihan's (2009) work, performance reforms are arguably intended to generate a 'purposeful' use of information. However, several authors have found that reforms appear to trigger more 'passive' responses (Taylor 2011a; Lavertu and Moynihan 2013). While a passive use may be necessary, its dysfunctional consequence is that large investments might be directed to ensuring compliance and to improving the quality of measurement systems, rather than to encouraging greater use of information to support decisions and actions (Moynihan 2009; Taylor 2011a). These findings prompted research into the drivers of various uses (e.g., Moynihan and Lavertu 2012).

Yet, little is known as to what happens when a particular use is introduced, how different types of uses coexist, and how the promoted use interacts with the existing ways of utilizing performance information. Even though a passive use may not lead to service improvement directly, providing compliance and assurance, monitoring and controlling are essential purposes of performance measurement (Behn 2003; Micheli and Neely 2010; Van Dooren et al. 2010) and cannot be discarded. Moreover, different stakeholders value different types of information and may use the same data differently. The study presented in this article aims to advance the understanding of these important dynamics by examining 
empirically the interplay of passive and purposeful uses of performance information within organizations.

\section{RESEARCH DESIGN}

This research is qualitative for three main reasons. First, most existing studies of the use of performance information are quantitative and have investigated the extent of performance information use, rather than the dynamics between different types of use (e.g., Taylor 2011b; Moynihan and Lavertu 2012; Kroll and Moynihan 2015). Similarly, scholars have often focused on one type of performance information use - usually the 'purposeful' one (Moynihan et al. 2012; Kroll 2015). The lack of prior research and the complexity inherent in examining multiple types of performance information use thus make a qualitative research design more suitable (see Edmondson and McManus 2007).

Second, in many quantitative studies various types of performance information use have loaded onto a single dimension, therefore 'this approach [has limited] our ability to understand subtle but potentially important nuances in the ways that managers use data for a variety of purposes' (Rabovsky 2014, p. 263). Some authors have used a qualitative approach, but looked primarily at the use of information either between organizations (e.g., Micheli and Neely 2010), or at the individual level (Döring et al. 2015). This has led to calls for qualitative studies to understand how and why performance information is used within organizations (Moynihan et al. 2012).

Finally, this research explores the range of experiences of different actors inside an organization, as well as their different perceptions. Previous studies relied mostly on single responses from either performance measurement specialists or agency heads. Therefore, respondents' familiarity with the measurement system and their use of performance 
information was greatly above average and not necessarily reflective of the variety of perspectives existing in organizations (Moynihan et al. 2011; Taylor 2011b). A qualitative design allows this variety of views to be captured and examined.

This research was carried out in England: in order to identify salient contextual aspects and establish the basis for generalization, it is useful to provide a description of the empirical setting.

\section{Empirical context}

The English context is particularly significant, because the past two decades have seen central government exert extensive control over the measurement and reporting of the performance of public sector organizations (Döring et al. 2015; Martin et al. 2016). Ensuring consistency of performance objectives, targets and indicators - the so-called 'golden thread' (Micheli and Neely 2010) - has been a priority for ministries and audit bodies (Audit Commission 2002), particularly in the $1997-2010$ period. Establishing a 'golden thread' was regarded as a key means to deploy national policies, increase reporting flows between different layers of government, and encourage the use of information to improve services (HM Treasury 2001; Local Government Association 2012).

Since the late 1990s, growing emphasis was placed on the role of measurement through the introduction of various initiatives aimed at producing an overall assessment of an organisation's performance (Martin et al. 2016). These included Best Value, Comprehensive Performance Assessments (CPA), Local Area Agreements (LAAs), and Comprehensive Area Assessments (CAA). In the second half of 2010 the new government announced that both LAAs and CAAs would be abolished, and auditing functions would progressively be given to 
external organizations and to the National Audit Office. Currently, voluntary peer reviews are being promoted and orchestrated by the Local Government Association.

Data for this study were collected in 2005-2007, hence in the period when considerable effort was being put in attempting to improve services through a centralized, performance measurement-based approach (Hood 2006; Döring et al. 2015). This makes the chosen context particularly significant as it provides the basis for generalising the findings to other settings where the measurement process is considered a driving force in service delivery and where various performance measurement practices are introduced in a mainly top-down fashion. For example, in England, certain sectors, such as education, continue to implement national frameworks to measure and manage performance (see, e.g., Teelken 2015). Moreover, the introduction and cascading of performance measurement frameworks from national to local levels is being adopted by many governments around the world (Johnston and Pongatichat 2008; Cheung 2011; Li 2015, Ma 2016). Similarly to the situation in England in the 2000s, in all such contexts the introduction of performance measurement systems is motivated by the goal of improving the efficiency and quality of services and, therefore, it is based on the assumption that performance information will be purposefully used to enhance service delivery (Gerrish 2016).

\section{Data collection and analysis}

First phase-identification of themes and selection of research sites

The research was carried out in two phases. The first one focused on the identification of the main themes related to uses of performance information and the selection of research sites. To this end, nine exploratory interviews, each lasting approximately one hour, were conducted with performance managers in nine public sector organizations. Given the 
exploratory nature of this phase, opportunistic sampling was utilized to capture sufficient diversity across the public sector in terms of both range and types of services provided. Organizations included: a police force, two healthcare trusts, a public museum, a housing association, a fire service, and three local authorities. The exploratory interviews enabled the researchers to examine various issues in relation to performance measurement and uses of performance information. For example, interviewees stressed the importance of reporting to government departments, but they also agreed that an increasing number of indicators was being introduced - both nationally and locally - to understand and improve local services.

Furthermore, the exploratory interviews helped select the sites for the in-depth analysis. In particular, respondents identified the service variety as a key factor to affect the measurability of performance (Mari 2007), which would in turn determine the extent and type of performance information use. Service variety refers to the range and complexity of services, which can vary from well defined and standardized (such as in police forces and fire authorities) to complex and often tailored to users' needs (such as in local authorities and healthcare organisations) (Slack et al. 2016). Moreover, various interviewees mentioned specific organizations known for their exemplary level of development of performance management practices, and this also informed the selection of the main research sites.

\section{Second phase - in-depth analysis}

The exploratory interviews led to a shortlist of four organizations: a healthcare organization, a police force, a fire authority, and a local authority. An initial screening showed that the fire authority and the local authority were the most suitable organizations for this study for four main reasons. First, they were sufficiently different with respect to service variety, thus providing the necessary diversity for maximizing learning (Pettigrew 1990). 
Second, these organizations were the most advanced in their performance measurement practices. Indications provided during the exploratory interviews were supported by the analysis of the two organizations' audits and reviews conducted by the Audit Commission. According to the auditors, a well-structured performance management framework had been developed and successfully implemented by the fire authority. The local authority had pro-actively developed its own version of the Balanced Scorecard (Kaplan and Norton 1992) in the early 2000s to equip itself with a comprehensive measurement system. This is significant because the quality of measurement systems is an important driver of performance information use (Taylor 2011b). Also, if organizations adopting more sophisticated practices were found incapable of using performance information purposefully, this would raise concerns for all organizations. Third, the auditors had also stated that both organizations were improving strongly and were demonstrating good performance despite operating in socially and economically deprived areas.

Finally, both organizations had been praised for organizational and political leadership, which are significant drivers of performance information use (Moynihan 2009). The Audit Commission emphasized that the fire authority's high performance was achieved through the 'strongest possible grade for political and professional leadership' and that the council's managerial leadership was at the root of service improvement.

\section{Data collection}

Triangulation was obtained through semi-structured interviews, analysis of written texts, and observations, as the first author spent several days on each site. This strengthened the validity of the research and enriched the understanding of the phenomena under investigation (Eisenhardt 1989). In both organizations, respondents were selected to obtain a plurality of 
viewpoints and therefore spanned multiple levels of hierarchy (see Table 1). In particular, there was an equal split in job roles between the respondents at both sites. At the fire authority, interviews lasted approximately 1.5 hours each and were carried out with: Chief Executive; Deputy Chief Executive; Head of Planning and Performance; Performance and Quality Manager; and two Performance Analysts. Given the clearly defined nature of their services, these interviews were sufficient to understand the organization's main performance measurement practices. At the local authority, where services were more varied and the set of performance indicators larger, 16 interviews of one hour on average were carried out with key informants at corporate level (Deputy Chief Executives), at service level (Heads of Service) and in more junior roles (Policy Officers, Assistant Managers and Performance Analysts).

TABLE 1 Empirical Phases of the Research

\begin{tabular}{|c|c|c|c|}
\hline $\begin{array}{c}\text { Empirical } \\
\text { phases }\end{array}$ & Purpose & $\begin{array}{l}\text { Organizations } \\
\text { studied }\end{array}$ & Main data sources \\
\hline $\begin{array}{l}\text { Exploratory } \\
\text { interviews }\end{array}$ & $\begin{array}{l}\text { Refining the } \\
\text { focus; } \\
\text { identifying } \\
\text { appropriate case } \\
\text { organizations }\end{array}$ & $\begin{array}{l}\text { Nine public sector } \\
\text { organizations }\end{array}$ & $\begin{array}{l}\text { Nine unstructured interviews of } \\
\text { approximately } 1 \text { hour with } \\
\text { performance managers }\end{array}$ \\
\hline \multirow{3}{*}{$\begin{array}{l}\text { In-depth } \\
\text { case studies }\end{array}$} & \multirow{3}{*}{$\begin{array}{l}\text { Providing } \\
\text { primary data for } \\
\text { answering the } \\
\text { research } \\
\text { questions }\end{array}$} & Fire authority & $\begin{array}{l}\text { Six semi-structured interviews and } \\
\text { two pilot interviews of the } \\
\text { approximate duration of } 1.5 \text { hours. } \\
\text { Relevant performance documents. }\end{array}$ \\
\hline & & Local authority & $\begin{array}{l}16 \text { semi-structured interviews and one } \\
\text { pilot interview of the approximate } \\
\text { duration of } 1 \text { hour. }\end{array}$ \\
\hline & & & Relevant performance documents. \\
\hline
\end{tabular}

The development of the interview protocol was informed by the literature and the first phase of the research. The protocol was piloted with the Head of Planning and Performance 
and a Principal Service Analyst at the fire authority, and with a Performance Analyst at the local authority. Initially, grand tour questions (McCracken 1988) were asked to enable informants to speak about their experiences and practices using their own terms. Next, questions were posed about the structure of the performance measurement systems and main reporting flows. Finally, aspects related to use of performance information were examined. To complement the interview data, multiple documents were collected - nine from the fire authority and 11 from the local authority. These include: annual reports, service scorecards, reports for auditors and regulators, strategic plans and risk management plans. Relevant information was also downloaded from the organizations' and their auditors' websites.

\section{Data analysis}

The first author analysed the data through a structured coding procedure supported by the QSR NVivo software. The results obtained were then reviewed and critiqued by the second author and conclusions were drawn using both literature-based concepts and ones emerging from the data. The analysis started from the description of data gathered through the identification of relevant quotes in the interviews and documents, proceeded to the iterative process of the composition and decomposition of codes, and then moved on to a more interpretative phase. Through thematic analysis (Fereday and Muir-Cochrane 2006) it was possible to identify, code, and categorize consistent patterns in the data. Finally, the first author examined in detail all existing performance indicators in both organizations with two performance analysts, and validated what was mentioned in the interviews against what was indicated in the documents.

The data analysis was conducted following the process proposed by Gioia et al. (2013) (see Figure 1). Specifically, through the first-order analysis many codes were 
identified and labelled using informant-centric terms. For example, some interviewees referred to auditors as 'their masters' and these passages were coded as 'master-slave relationship with auditors'. Second-order categories were obtained utilizing researchercentric concepts. For example, 'master-slave relationships with auditors' were regarded as instances of 'compliance and reporting'. Finally, aggregate theoretical dimensions were defined in order to best explain what was found in relation to uses of performance information (Gioia et al. 2013). In this case, 'compliance and reporting' was considered an example of 'passive use of performance information.' Tables 2 and 3 illustrate this process in more detail. Results of the coding process are examined in the following section.

\section{FIGURE 1 Coding Structure}

\section{First-order codes}

Reporting to stakeholders

- Performance information to enable the reporting process

- Master-slave relationship with auditors

- Focus on externally developed targets and indicators

- Targets are objectives

- Understanding performance

- Allocating resources

- Quantitative and qualitative information

- Focus on selected indicators

- Providing and receiving feedback

- Aligning measurement to objectives

- Performance information to drive improvement

- External reporting and internal resources

- Importance of both externally- and internally-developed indicators

- External reporting and performance improvement

- Use of the same information for reporting and performance improvement purposes

- Introduction of 'stretch targets' in relation to national indicators \begin{tabular}{ll} 
Second-order codes & Aggregate dimensions \\
\hline
\end{tabular}

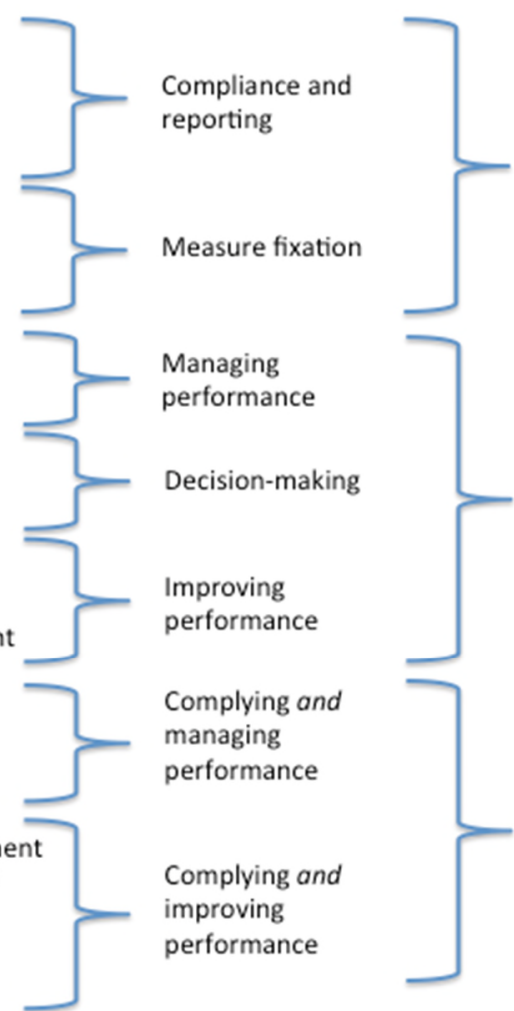

Passive use of performance information

Purposeful use of performance information Joint passive and purposeful uses of performance information 
TABLE 2 Passive and Purposeful Uses of Performance Information

\begin{tabular}{lll}
\hline $\begin{array}{c}\text { Second-order } \\
\text { codes }\end{array}$ & \multicolumn{1}{c}{$\begin{array}{c}\text { First-order } \\
\text { codes }\end{array}$} & \multicolumn{1}{c}{ Representative quotes } \\
$\begin{array}{l}\text { Compliance and } \\
\text { reporting }\end{array}$ & $\begin{array}{l}\text { Reporting to } \\
\text { stakeholders }\end{array}$ & $\begin{array}{l}\text { Performance information 'is also used to report progress of } \\
\text { performance to the stakeholders, like the corporate } \\
\text { management team, the [Board] members, [the regulators] or } \\
\text { the department for communities and local government.' } \\
\text { (Head of Revenues and Benefits, Local authority) }\end{array}$ \\
& $\begin{array}{l}\text { Performance } \\
\text { information to } \\
\text { enable the } \\
\text { reporting } \\
\text { process }\end{array}$ & $\begin{array}{l}\text { Performance reports 'are published on a monthly basis and } \\
\text { that's to assist [area commanders] in their management, } \\
\text { ultimately for [national] performance indicators. It's just } \\
\text { supporting evidence' (Performance analyst, Fire authority) }\end{array}$ \\
$\begin{array}{l}\text { Master-slave } \\
\text { relationship with } \\
\text { auditors }\end{array}$ & $\begin{array}{l}\text { 'We know that [the auditors] are our masters, if you want. } \\
\text { We just try and achieve what they set us' (Performance and }\end{array}$ \\
Quality Manager, Fire authority)
\end{tabular}

Decisionmaking
Quantitative and qualitative information
To make decisions, 'we've built up quantitative performance measures of course determined and driven largely by the government's performance indicator, but also qualitative observational bank of evidence around performance. The two taken together are fundamental.' (Corporate Director of Children's Services, Local authority) 
Focus on selected indicators
'When you have 400 indicators it's tough to do that, when you've got a core basket of a dozen or 20 , you can do it. We only really focus on the top 20 in the department at any one time for real management action.' (Corporate Director of Customer Services, Local authority)

$\begin{array}{ll}\text { Improving } & \begin{array}{l}\text { Providing and } \\ \text { receiving } \\ \text { feedformance }\end{array}\end{array}$

Aligning measurement to objectives

Performance information to drive improvement
'The [auditors'] approach was to take a more holistic view of the performance of the organization, identify the relative relevance of each indicator and then being prepared to listen to our explanations.' (Deputy CEO, Fire authority)

Our performance 'has improved dramatically and I think the work we've done about those PIs within the Balanced Scorecard ... contributes to that overall success of the organization' (Head of Leisure, Arts and Culture, Local authority)

Performance measurement 'is the key driver for improvement ... Without the performance indicators ... the pressure from those indicators, we would never have noticed there was another way of doing it and therefore the performance indicators had a direct impact on practice' (Director of Children's Services, Local authority).

TABLE 3 Combined Passive and Purposeful Uses of Performance Information

\begin{tabular}{lll}
\hline $\begin{array}{c}\text { Second-order } \\
\text { codes }\end{array}$ & \multicolumn{1}{c}{$\begin{array}{c}\text { First-order } \\
\text { codes }\end{array}$} & \multicolumn{1}{c}{ Representative quotes } \\
\hline $\begin{array}{l}\text { Complying and } \\
\text { managing } \\
\text { performance }\end{array}$ & $\begin{array}{l}\text { External } \\
\text { reporting and } \\
\text { internal } \\
\text { resources }\end{array}$ & $\begin{array}{l}\text { 'The culture within local government is now about } \\
\text { performance, you know where you fit in that league table, } \\
\text { what's your rating, but there is a lot in terms of reputation, } \\
\text { attracting a good workforce ... raising aspirations in the } \\
\text { community ... it's all about having a good, well performing } \\
\text { organization.' (Balanced Scorecard Project Manager, Local } \\
\text { authority) }\end{array}$ \\
& $\begin{array}{l}\text { Importance of } \\
\text { both externally- } \\
\text { and internally- } \\
\text { developed } \\
\text { indicators }\end{array}$ & $\begin{array}{l}\text { 'We have been focusing mostly on the [national KPIs] that } \\
\text { are critical ... because of the reward grants and just the status } \\
\text { that we have that are not critical [nationally] are also very } \\
\text { useful. (Corporate Director of Customer Services, Local } \\
\text { authority) }\end{array}$ \\
\hline
\end{tabular}




\begin{tabular}{lll}
\hline $\begin{array}{l}\text { Complying and } \\
\text { improving } \\
\text { performance }\end{array}$ & $\begin{array}{l}\text { External } \\
\text { reporting and } \\
\text { performance } \\
\text { improvement }\end{array}$ & $\begin{array}{l}\text { 'The main reason for [measuring performance] is to make } \\
\text { sure that the children that I work with turn out to be well } \\
\text { adjusted individuals and have a decent life. That's the } \\
\text { primary thing. The other thing of course is that local } \\
\text { government is funded through public funds, public money ... } \\
\text { so there's something about making sure that we spend our } \\
\text { money well' (Head of Children's Safeguarding and Rights, } \\
\text { Local authority) }\end{array}$ \\
& $\begin{array}{l}\text { Use of the same } \\
\text { information for } \\
\text { reporting and } \\
\text { performance } \\
\text { improvement } \\
\text { purposes }\end{array}$ & $\begin{array}{l}\text { 'It's not that we just produce figures for [the auditors], we're } \\
\text { actually having to use those figures to work from, the end } \\
\text { result is obviously we hope to improve our performance and } \\
\text { meet our targets ... [performance information] is not just } \\
\text { used for them, it's a working tool' (Assistant Manager, Local } \\
\text { authority) }\end{array}$ \\
& $\begin{array}{l}\text { Introduction of } \\
\text { 'stretch targets' } \\
\text { in relation to } \\
\text { national } \\
\text { indicators }\end{array}$ & $\begin{array}{l}\text { 'For ... home fire safety checks [indicator] there was a } \\
\text { conscious decision by this organization because, whilst there } \\
\text { is a national target of 20\% reduction, we decided that we } \\
\text { could do better than that, and in fact we set in our } \\
\text { performance plan a target of 33\% reduction.' (Deputy CEO, }\end{array}$ \\
& Fire authority)
\end{tabular}

\section{FINDINGS}

Despite differences between the two chosen organizations, a large number of similarities emerged from the analysis. Firstly, the perception of various aspects of performance information use, such as the links between performance measurement and improvement in both organizations, was very similar. Importantly, the observed patterns in the use of performance information were also the same. Such similarity of findings has two effects: firstly, it enhances the generalizability of the results across different organizations operating within a comparable performance regime; secondly, it allows the findings to be treated as a single dataset, as little is to be gained from comparing the two sites more formally. Therefore, the findings are presented according to the main themes identified during data analysis. 


\section{Passive or Purposeful Uses}

In both organizations the interviewees expressed different views about uses of performance information. Although the questions explicitly avoided referring to specific uses, the analysis clearly identified two main types - passive and purposeful - in line with Moynihan's (2009) classification. As shown in Table 2, a passive use was mainly related to compliance and reporting as well as to the emphasis on the measurement process, which could lead to 'measure fixation', i.e., placing emphasis on performance indicators rather than on the underlying objectives (Smith 1995). Specifically, interviewees highlighted the central role of various stakeholders - principally auditors and central government - in performance measurement and reporting. Several respondents related the measurement process almost exclusively to externally developed targets and indicators, and conflated performance targets, often set nationally, with strategic organizational objectives, regardless of whether achieving these objectives would result in securing additional resources for the organization.

A purposeful use was more concerned with the wider performance management process as well as with information being utilized to support decisions and improve services. In particular, many interviewees emphasized the role of performance information in enabling staff to understand performance at organizational and individual levels, allocate resources, and trigger process improvement. While attention was paid to the type of information being collected and utilized (quantitative and qualitative), the kind of indicators used (strategic or operational), and the linkages between indicators and objectives, such remarks were always related to the effects of performance measurement, rather than to the measurement process perse.

Differences between passive and purposeful were also reflected in the internal documents. For example, at the Local Authority the main aim of the organization's strategy and measurement system was "to give all those partners involved, especially local 
communities, a clear sense of purpose" (Strategic Plan), whereas performance measurement documents focused on data quality and reporting, without mentioning the links between the use of data and service improvement. For example, the Introduction to the Children's Services Performance Dataset Monitoring Tool stated: "it is essential that every effort is made to ensure that the information contained within this document is an accurate and reflective picture of the performance of Children's Social Services. We want to ensure that the good work being done at the front-line of the service is reflected within."

\section{Combined Passive and Purposeful Uses}

Quotes reported in Table 3 confirm and extend what was found in previous studies in relation to passive and purposeful categories. Importantly, however, further analysis of the data shows that these are not two separate, mutually exclusive elements. In fact, respondents who emphasized the purposeful use of performance information also noted the importance of reporting to external stakeholders. In particular, twelve interviewees explicitly articulated the link between external reporting and securing resources, especially funding and more skilled employees, pointing out the complementarity of externally and internally developed indicators. For example, in a passage reported in Table 3, the Balanced Scorecard Project Manager at the local authority clearly legitimizes and highlights a passive use ("you know where you fit in that league table, what's your rating'), but complements it with remarks on a more active and purposeful use, referring to employee recruitment and organizational performance.

Compliance was also related to performance improvement, for example when externally requested information could be utilized to enhance service delivery, and when external targets could serve to define internal 'stretch targets', as exemplified in the passage 
by the fire authority's Deputy CEO in Table 3. Furthermore, auditors appeared to play an active role in fostering a positive connection between passive and purposeful uses of information. For example:

[The auditors' current] view is very much that [performance measurement] is a process to achieve improvement, so we want to identify the areas where you need to develop to improve ... rather than just come in and just look at the performance and say: 'this isn't very good therefore you must be doing things wrong'. They helped us not just to identify the areas for development, but they also assisted us and continue to assist us to develop and improve to achieve more effective services. (Deputy CEO, Fire authority)

\section{Interplay of Performance Information Uses}

The interviewees' responses clearly showed that different understandings and uses of performance information coexisted in both organizations. However, for ten respondents, performance information was considered useful only as long as it allowed them to produce reports that would stand up to external scrutiny (see Table 4). As a consequence, accuracy and timeliness were the key criteria to assess the quality of performance information, and its use was predominantly passive. For the other interviewees, performance information was important for both providing evidence and asking and addressing questions about performance improvement. Therefore, the contraposition was not between passive and purposeful uses as suggested in earlier studies, but between a mere passive use for some people and a combination of passive and purposeful for others. 
TABLE 4 Differences in uses between hierarchical levels

\begin{tabular}{llcc}
\hline & & $\begin{array}{c}\text { Predominantly } \\
\text { passive use }\end{array}$ & $\begin{array}{c}\text { Combined passive } \\
\text { and purposeful } \\
\text { uses }\end{array}$ \\
\hline Senior Managers & $\begin{array}{l}\text { Local authority } \\
\text { Fire authority }\end{array}$ & 1 & 7 \\
\hline $\begin{array}{l}\text { Middle Managers } \\
\text { and frontline } \\
\text { staff }\end{array}$ & Local authority & 5 & 2 \\
\hline
\end{tabular}

Approximately half of the respondents believed that performance information should indeed be collected and reported, but mainly as a means to support service improvement rather than an end in itself; as the Director of Children Services at the local authority stated: 'It's not just a number crunching capacity, it's an intelligence.'

On the contrary, others articulated a clearly passive use and appeared to believe that they were adding value through compliance and reporting. For example, while discussing recent changes to the local authority's measurement system, a performance analyst in social services stated:

Now that we monitor on a weekly basis, [social workers] know they've got to record [visits to children] or they're going to have somebody jumping up and down and asking them why, just to record the fact that they've done it. So, the whole culture has helped us to increase our recording practices.

Interestingly, differences in use appeared to be most pronounced between organizational levels. As shown in Table 4, a combined passive and purposeful use was prevalent on senior management level. This is perhaps not surprising, considering the 
positive assessments both organizations received from the auditors, particularly in relation to the role of leadership. On the other hand, at middle management level and below, a passive use of performance information was dominant, with its emphasis on specific indicators, the technical aspects of measurement, the achievement of targets, and external orientation.

Crucially, the more junior staff's focus on the passive use did not appear to be driven by an intention to avoid the priorities set by senior management. On the contrary, they believed that a passive use was precisely what senior managers were attempting to promote. As the quotes in Table 2 illustrate, these respondents genuinely considered the provision of robust information to external bodies as the ultimate purpose of performance measurement and therefore understood improvement as enhancement of the accuracy and timeliness of their reports. Surprisingly, this was despite the fact that much of this information was directly related to their tasks and operations and, therefore, could be used locally to improve service delivery.

Senior managers seemed aware that closing the gap between a combined passive and purposeful use of information on one hand and a persistent commitment to the passive use on the other required painstaking work on changing the way people understood and made sense of performance measurement. For example, the Deputy CEO of the fire authority stated:

We've been working very hard over the last four years to break down [the perception of performance measurement as a punitive arrangement], but people's perceptions quite often lags behind what's actually occurring, so I think it might take some time for them to realise that things have actually changed. 
Thus, strengthening the internal 'golden thread' (Micheli and Neely 2010) and creating a more complete understanding of the use of performance information throughout the organization required time and effort. Communication was regarded as fundamental. As a middle manager in the local authority stated: 'internally it does take quite a long time for that continuity, that message about what you're trying to achieve to work its way to all levels of the organization'. A proactive and collaborative role of the CEO was seen as necessary to spread the combined understanding of performance information use:

I think [the new CEO] has changed the regime, we've got different people, we've got a much more collaborative approach ... [the previous CEO] was monitoring our failures, if you like, and marking our homework, and today we're working together, I think there's no question about that. (Corporate Director of Customer Services, Local authority)

Reducing the gap between a complex view of performance information and a simpler one required continuous work on changing deep-seated perceptions about the roles of performance measurement on the part of the organizations and their leaders.

\section{DISCUSSION AND CONCLUSIONS}

This research examines the complexity inherent in one of the most crucial aspects of performance measurement and management - the use of performance information. In particular, it investigates the interplay between two types of performance information use passive and purposeful. The former regards performance measurement as a means to ensure monitoring, control and reporting (Hood 2006), the latter to improve efficiency and effectiveness (Moynihan 2009). 
This study makes four important contributions to both theory and practice. First, although the literature identifies the ideal types of performance information use and acknowledges that these can coexist in an organization, different types of use are often treated in a discrete and contrasting way. For example, Taylor (2009) clearly separated the use of performance information for external reporting from that for internal decision making; Kroll and Vogel (2014) hypothesized the externally driven and internally oriented uses of performance information as distinct and influenced by different sets of factors. This study, instead, suggests that it may be equally, if not more important to understand and examine the difference between a combined (passive and purposeful) use of performance information employed by some people and an exclusively passive use persistently adhered to by others.

Second, the split between organizational levels in the way individuals used performance information is noteworthy for various reasons. First of all, both organizations were recognized as advanced in the implementation of performance management and therefore all employees could be expected to use performance information purposefully, at least to some extent. Yet, this was not the case, as the data revealed a consistent gap between senior management using performance information both purposefully and passively and frontline staff focusing on the passive use. The lack of the purposeful use of performance information at the frontline is particularly problematic, given the proximity of staff to service delivery and to using this information to enhance services. If the intent of performance management reforms is to improve government performance (Moynihan et al. 2011), this should be regarded as a primary area of concern.

Third, this research extends the theoretical understanding of the dynamics of performance information use and points out possible issues with the broader theoretical assumptions underlying existing work. As a theory building study, this research makes a step towards progressing the conversation about the use of performance information beyond 
typologies (Moynihan 2009) or lists of antecedents and instead provides insight into the dynamics between specific types of use. For example, the split between different uses of performance information has been theorized as evidence of decoupling (Modell 2003), where organizations separate performance indicators for external reporting from indicators related to service improvement (Taylor 2009). The inductive design of this study, however, introduces additional nuance into this theorizing, showing that such decoupling may in fact not be deliberate: those focusing mainly on conforming to procedural requirements saw compliance as the principal goal of performance measurement and believed that senior management's efforts to increase performance information use were aimed at improving reporting, rather than at supporting internal decision-making and, ultimately, enhancing services. This suggests that decoupling in the uses of performance information should not necessarily be treated as a strategic response aimed at actively separating diverging interests (Greenwood et al. 2011) or 'building gaps between (...) formal structures and actual work activities' (Meyer and Rowan 1977, p. 341). Instead, the co-existence of the combined use and the exclusively passive one can be seen as manifestation of divergent sensemaking (Maitlis and Christianson, 2014), where individuals interpret and explain the goals and purposes of performance management differently.

Moreover, this view of the dynamics of decoupling has important implications for understanding the drivers of performance information use. For example, while leadership was identified as an important factor by interviewees (see also Moynihan et al. 2012), the sheer force of the leaders' commitment to implementing performance management was not sufficient to promote a purposeful use, especially at the frontline. A deeper understanding of the reasons for different views regarding the role of performance information seems to be a required complement to the leaders' drive. The findings thus suggest that the view of leadership in this context may need to go beyond a simple commitment to performance 
management (Kroll and Moynihan 2015) or an encouragement to observe the rules and procedures set by the government (Tummers and Knies 2016). As the passive use by some individuals may be caused by the way they make sense of the purposes of performance management, leaders may need to address the sensemaking processes directly (Maitlis and Christianson 2014). In particular, they may first have to encourage staff to question their existing perceptions of performance measurement and the corresponding use of performance information, and to re-examine their course of action. Subsequently, leaders would need to propose alternative explanations and new practices to help individuals understand the broader application of performance management and recognize opportunities for a purposeful use of information.

More broadly, this research calls into question the "behavioural assumption", which underlies much of the theory and practice of performance measurement and which presupposes that measurement systems directly influence behaviours (Hall 2008; Micheli and Mari 2014). Past and current reforms share this assumption and regard the purposeful use of performance information as a fundamental enabler of positive behaviours. This research shows that the "behavioural assumption" warrants further investigation, as a passive use of performance information may invalidate it, even when there is an explicit effort by senior management to link measurement with improvement.

Fourth, the results of this study also extend recommendations proposed in earlier research. For example, Kroll (2015, p. 212) argues that 'to improve information use, it seems to be promising to convince managers of the advantages of performance management and to form a critical mass of promoters.' While this research does not dispute this statement, great attention should be paid to which use - or uses - should be promoted, on which level, and for what reasons. 
Moreover, being aware of the tension between combined and passive uses makes it easier to direct initiatives aimed at increasing the purposeful use. Differences in use may be expected - indeed, it would be naïve to assume that a CEO and a social worker would use the same piece of information in identical ways. Equally, some information may be relevant at one level, but not at another. Requiring a purposeful use of the same data at every level is therefore unrealistic. Instead, creating sufficient awareness of how information is used by different parties may become an important goal. For example, the same piece of information may be used 'purposefully' but in different ways, as a senior manager could use information related to a project's performance to launch a new project, whereas a middle manager may use the same information to change the allocation of resources within the existing project. Alternatively, the senior manager may use this information 'passively' by simply reporting to central government, whereas the middle manager could utilize it purposefully. What matters, therefore, is not the complete alignment of uses, but a clear view about what role information is expected to play in each instance.

In terms of implications for practice, this study suggests that, at the organizational level, senior managers aiming to promote a purposeful use may first need to identify how information is currently being utilized, and then engage with individuals who mainly use information passively. This should not result in entirely dismissing the passive use, but rather in exposing staff to alternative uses and educating them about the benefits of utilizing performance information to trigger service improvement. Similarly, if reforms intend to promote a purposeful use of information (Local Government Association 2012), consideration should be given to how national frameworks are going to be interpreted by local actors at different organizational levels. This extends Taylor's (2011a) observation that external forces are considerably less significant in driving the use of performance information for internal decision-making. Our study suggests that it may indeed be more important to 
understand how different internal stakeholder groups will utilize specific indicators. While some performance information may be intended mainly for external reporting - on basic expenditure and headcount, for example - other information may be collected with the explicit aim of triggering improvement, e.g., for national benchmarking schemes on citizens' satisfaction with local services. Therefore, not only may it be difficult to clearly separate two ideal types in an empirical setting and generally promote the purposeful use, but focusing exclusively on the purposeful use may actually be inappropriate. Moreover, auditors should try to understand not only whether performance measurement practices are established in an organization, but also how these relate to service improvement.

This study has limitations that could inform future research. The procedure used for selecting the research sites and the similarity of findings across two organizations chosen for their diversity suggest that the findings could be extended to a range of public sector organizations. However, only two organisations were considered and the context of this research is characterized by a prescriptive national performance framework intended to monitor and improve the performance of local organizations. Therefore, the findings are generalizable to similar contexts and may not apply equally in different environments. In England, the general performance management regime has evolved and become less centralized and normative, but the findings continue to be relevant to specific sectors, such as education.

Quantitative research could test the concurrent existence of different uses within organizations, and investigate differences between hierarchical levels, although these would require surveying multiple respondents from the same organization. Qualitative studies could examine the contraposition between a combined and a merely passive use in different performance regimes. Also, a longitudinal approach could bring further insights, for example 
in relation to changing roles of audit bodies and to the introduction of alternative approaches to performance measurement at the national level.

This study has documented the differences in the way performance information was used across different hierarchical levels. People's perceptions, however, are also affected by their functional background (Moon 2017), and future work may explore the effect of functional bias on the use of performance information. Moreover, this article focused mainly on the internal stakeholders' uses of routine performance information. Future studies could explicitly investigate the use of non-routine performance information and apply multiple constituency theory (Campbell and Lambright 2016) to examine the differences in the perception and use of performance information between external stakeholders, such as central government agencies, regulators, funders, and citizens. Finally, future research could consider whether the way performance information is used depends on whether the performance is above or below the target (Nielsen 2014) and examine the effects of performance information on service improvement. 


\section{REFERENCES}

Arnaboldi, M., I. Lapsley and I. Steccolini. 2015. 'Performance Management in the Public Sector: the Ultimate Challenge', Financial Accountability and Management, 31, 1, 1-22. Audit Commission. 2002. Acting on Facts: Using Performance Measurement to Improve Local Authority Services. London: Audit Commission.

Behn, R. 2003. 'Why Measure Performance? Different Purposes Require Different Indicators', Public Administration Review, 63, 5, 586-606.

Bevan, G. and C. Hood. 2006. 'What's Measured is What Matters: Targets and Gaming in the English Public Health Care System', Public Administration, 84, 3, 517-538.

Bovaird, T. and D. Gregory. 1996. 'Performance Indicators: The British Experience'. In A. Halachmi and G. Bouckaert (eds), Organisational Performance and Measurement in the Public Sector. Westport: Greenwood.

Bryson, J. 2012. 'Performance Information Use and Accountability'. Public Administration Review, 79, S1, 105-7.

Campbell, D. and K.T. Lambright. 2016. 'Program Performance and Multiple Constituency Theory', Nonprofit and Voluntary Sector Quarterly, 45, 1, 150-171.

Cheung, A. 2011. 'NPM in Asian Countries'. In Christensen, T. and P. Laegreid (eds), The Ashgate Research Companion to NPM. Surrey: Ashgate.

Destler, K. 2015. 'A Matter of Trust: Street Level Bureaucrats, Organizational Climate and Performance Management Reform', Journal of Public Administration Research and Theory, 27, 3, 517-534.

Döring, H., J. Downe and S. Martin. 2015. 'Regulating Public Services: How Public Managers Respond to External Performance Assessment', Public Administration Review, 75, 6, 867-77. 
Edmondson, A. and S. McManus. 2007. 'Methodological Fit in Management Field Research', Academy of Management Review, 32, 4, 1155-79.

Eisenhardt, K. 1989. 'Building Theories from Case Study Research', Academy of Management Review, 14, 4, 532-50.

Fereday, J. and E. Muir-Cochrane. 2006. 'Demonstrating Rigor Using Thematic Analysis: A Hybrid Approach of Inductive and Deductive Coding and Theme Development', International Journal of Qualitative Methods, 5, 1, 80-92.

Gioia, D., K. J. Corley and A. Hamilton. 2013. 'Seeking Qualitative Rigor in Inductive Research: Notes on the Gioia Methodology', Organizational Research Methods, 16, 1, $15-31$.

Gerrish, E. 2016. 'The Impact of Performance Management on Performance in Public Organizations: A Meta-Analysis’, Public Administration Review, 76, 1, 48-66.

Greenwood, R., M. Raynard, F. Kodeih, E.R. Micelotta and M. Lounsbury. 2011. 'Institutional Complexity and Organizational Responses', The Academy of Management Annals, 5, 1, 317-371.

HM Treasury. 2001. Choosing the Right Fabric - A Framework for Performance Information. An HM Treasury report available at https://www.nao.org.uk/wpcontent/uploads/2013/02/fabric.pdf [accessed 26 October 2016].

Hood, C. 2006. 'Gaming in Targetworld: The Targets Approach to Managing British Public Services', Public Administration Review, 66, 4, 515-21.

Johnston, R. and P. Pongatichat. 2008. 'Managing the Tension Between Performance Measurement and Strategy: Coping Strategies', International Journal of Operations and Production Management, 28, 10, 941-967.

Kaplan, R.S. and D. Norton. 1992. 'The Balanced Scorecard - Measures That Drive Performance', Harvard Business Review, 70, 1, 71-79. 
Kroll, A. 2015. 'Explaining the Use of Performance Information by Public Managers: A Planned-Behavior Approach', American Review of Public Administration, 45, 2, 20115.

Kroll, A. and D. P. Moynihan. 2015. 'Does Training Matter? Evidence from Performance Management Reforms', Public Administration Review, 75, 3, 411-20.

Kroll, A. and D. Vogel. 2014. 'The PSM-Leadership Fit: A Model of Performance Information Use', Public Administration, 92, 4, 974-91.

Lavertu, S. and D. P. Moynihan. 2013. 'Agency Political Ideology on Reform Implementation: Performance Management in the Bush Administration', Journal of Public Administration Research and Theory, 23, 3, 521-49.

Li, J. 2015. 'The Paradox of Performance Regimes: Strategic Responses to Target Regimes in Chinese Local Government', Public Administration, 93, 4, 1152-1167.

Local Government Association 2012. Performance Management. Report available at http://www.local.gov.uk/documents/10180/7530798/L12_210+performance+mgmt+wo $\underline{\text { rkbook+final 22210.pdf/ee67942c-67ba-456b-b6f8-9ff17e15c3e2 [accessed } 26 \text { October }}$ 2016].

Ma, L. 2016. 'Performance Feedback, Government Goal-Setting and Aspiration Level Adaptation: Evidence from Chinese Provinces', Public Administration, 94, 2, 452-471.

Maitlis, S., and Christianson, M. 2014. 'Sensemaking in Organizations: Taking Stock and Moving Forward', The Academy of Management Annals, 8, 1, 57-125.

Mari, L. 2007. 'Measurability', in Boumans, M. (Ed.), Measurement in Economics. London: Elsevier.

Martin, S., S. Nutley, J. Downe and C. Grace. 2016. 'Analysing Performance Assessment in Public Services: How Useful is the Concept of a Performance Regime?', Public Administration, 94, 1, 129-145. 
McCracken, G. 1988. The Long Interview. Newbury Park, CA: Sage.

Meyer, J.W. and B. Rowan. 1977. 'Institutionalized Organizations: Formal Structure as Myth and Ceremony', American Journal of Sociology, 83, 3, 340-363.

Micheli, P. and A. Neely. 2010. 'Performance Measurement in the English Public Sector: Searching for the Golden Thread', Public Administration Review, 70, 4, 591-600.

Micheli, P. and L. Mari. 2014. 'The Theory and Practice of Performance Measurement', Management Accounting Research, 25, 2, 147-156.

Modell, S. 2003. 'Goals versus Institutions: The Development of Performance Measurement in the Swedish University Sector', Management Accounting Research, 14, 4, 333-359.

Moon, K. 2017. 'The Effects of Diversity and Transformational Leadership Climate on Organizational Citizenship Behavior in the U.S. Federal Government: An Organizational-Level Longitudinal Study’ Public Performance and Management Review, 40, 2, 361-381.

Moynihan, D. P. 2009. 'Through a Glass Darkly: Understanding the Effects of Performance Regimes', Public Performance and Management Review, 32, 4, 586-98.

Moynihan, D. P., S. Fernandez, S. Kim, K. M. LeRoux, S. Piotrowski, B. Wright and K. Yang. 2011. 'Performance Regimes amidst Governance Complexity' Journal of Public Administration Research and Theory, 21, S1, i141-55.

Moynihan, D. P. and A. Kroll. 2016. 'Performance Management Routines That Work? An Early Assessment of the GPRA Modernization Act', Public Administration Review, 76, 2, 314-23.

Moynihan, D. P., and S. Lavertu. 2012. 'Does Involvement in Performance Management Routines Encourage Performance Information Use? Evaluating GPRA and PART', Public Administration Review, 72, 4, 592-602. 
Moynihan, D. P., S. Pandey and B. Wright. 2012. 'Setting the Table: How Transformational Leadership Fosters Performance Information Use', Journal of Public Administration Research and Theory, 22, 1, 143-64.

Pettigrew, A. 1990. 'Longitudinal Field Research on Change: Theory and Practice', Organization Science, 1, 3, 267-92.

Rabovsky, T. 2014. 'Using Data to Manage for Performance at Public Universities', Public Administration Review, 74, 2, 260-72.

Slack, N., A. Brandon-Jones and R. Johnston. 2016. Operations management. $8^{\text {th }}$ edn. Pearson.

Smith, P. 1995. 'On the Unintended Consequences of Publishing Performance Data in the Public Sector', International Journal of Public Administration, 18, 2-3, 277-310.

Speklé, R. and F. H. M. Verbeeten. 2014. 'The Use of Performance Measurement Systems in the Public Sector: Effects on Performance', Management Accounting Research, 25, $131-146$.

Taylor, J. 2009. 'Strengthening the Link between Performance Measurement and Decision Making', Public Administration, 87, 4, 853-71.

Taylor, J. 2011a. 'Strengthening the Link between Performance Measurement and Decision Making', Public Administration, 89, 3, 860-78.

Taylor, J. 2011b. 'Factors Influencing the Use of Performance Information for Decision Making in Australian State Agencies', Public Administration, 89, 4, 1316-34.

Teelken, C. 2015. 'Hybridity, Coping Mechanisms, and Academic Performance Management: Comparing Three Countries', Public Administration, 93, 2, 307-323.

Tummers, L. and E. Knies. 2016. 'Measuring Public Leadership: Developing Scales for Four Key Public Leadership Roles', Public Administration, 94, 2, 433-51. 
Van Dooren, W., G. Bouckaert and J. Halligan. 2010. Performance Management in the Public Sector. Abingdon: Routledge. 